\title{
EL EJERCICIO DEL DERECHO DE SUFRAGIO POR LOS MILITARES ESPAÑOLES EN EL EXTRANJERO. EXAMEN CRÍTICO DEL PROCEDIMIENTO ESPECIAL DE VOTACIÓN PREVISTO EN LA ORDEN 116/1999
}

\author{
POR \\ LUIS A. GÁLVEZ MUÑOZ \\ Profesor Titular de Derecho Constitucional \\ de la Universidad de Murcia
}

\section{INTRODUCCIÓN}

El Derecho Constitucional es el Derecho que regula los elementos básicos del poder y la libertad en la sociedad estatal. Sienta, por ello, las bases de la organización y funcionamiento del Estado y configura los derechos fundamentales de los ciudadanos y sus garantías. Es él quien se ocupa, por tanto, de definir el sistema jurídico-político de una sociedad que tiene a la libertad como fin. Dicho en pocas palabras, el

* Este trabajo se enmarca dentro del proyecto de investigación sobre «Revisión y mejora del Derecho Electoral» (Código VEJ 2005-09295/JURI) subvencionado por el Ministerio de Educación y Ciencia y por los Fondos FEDER de la Unión Europea. 
Derecho Constitucional es el Derecho fundamental del llamado «Estado de Derecho" ${ }^{1}$.

Si esto es así, es evidente que el Derecho Constitucional tiene mucho que decir en relación con las Fuerzas Armadas, dada la importancia que las mismas tienen para el Estado. En ellas, junto con las Fuerzas y Cuerpos de Seguridad del Estado, reside el monopolio de la fuerza legítima que corresponde el Estado, teniendo como función primordial la defensa de éste frente a los enemigos exteriores e incluso, en ciertos casos, frente a los enemigos del interior ${ }^{2}$.

Son, por ello, muchos los preceptos que la Constitución española, en cuanto norma por excelencia del Derecho Constitucional español, dedica a esta materia. El caso más conocido, por importante y polémico, es el artículo 8, consagrado a determinar el papel de las Fuerzas Arma-

1 Sobre el concepto de Derecho Constitucional Vid. Ángel Garrorena Morales, "Cuatro tesis y un corolario sobre el Derecho Constitucional", Revista Española de Derecho Constitucional, núm. 51, 1997, pp. 37-64 (también en Estudios de Derecho Constitucional y de Ciencia Política. Homenaje al profesor Rodrigo Fernández-Carvajal, Universidad de Murcia, Murcia, 1997, pp. 337-366). Vid. también, entre otros, Mariano García CANALES, "Notas sobre el método y los límites de la interpretación en Derecho Constitucional», en Estudios de..., op. cit., pp. 287-314; Francisco RuBıo LLORENTE "Derecho Constitucional», en Alfredo Montoya Melgar (director), Enciclopedia Jurídica Básica, Civitas, Madrid, 1995; Eliseo AJA FERNÁNDEZ: «Derecho Constitucional», en José J. Ferreiro, Juan Miouel y Pablo SALVAdor (eds.), La enseñanza del Derecho en España, Tecnos, Madrid, 1987; y Eduardo García DE EnTERRíA, La Constitución como norma y el Tribunal Constitucional, Civitas, Madrid, 1981.

2 En lógica correspondencia la doctrina ha estudiado esta materia. Limitándonos a las obras más generales cabe citar Roberto L. BLANCO VALDÉS, La ordenación constitucional de la defensa, Madrid, Tecnos, 1988; Miguel Domínguez-BERRUETA DE JUAN y otros., Constitución, policía Fuerzas Armadas, Madrid, Marcial Pons, 1997; Joaquín BLANCo ANDE, Defensa nacional y Fuerzas Armadas, Madrid, Dykinson, 1987; Lorenzo СотіNo Hueso, El modelo constitucional de Fuerzas Armadas, Madrid, Instituto Nacional de Administración Pública y Centro de Estudios Políticos y Constitucionales, 2002; Francisco Fernández SEgAdo, «El estatuto jurídico-constitucional de las Fuerzas Armadas y su desarrollo legislativo: balance de un cuarto de siglo", en Revista Española de Derecho Constitucional, n. ${ }^{\circ}$ 70, 2004, pp. 189-232; Fernando LóPEZ RAMÓN, La caracterización jurídica de las Fuerzas Armadas, Madrid, Centro de Estudios Constitucionales, 1987; Manuel RAMíREZ JIMÉNEZ (ed.), La función militar en el actual ordenamiento constitucional español, dirección de Fernando López Ramón y coordinación de Javier Fernández López, Madrid, Trotta, Fundación Centro de Estudios Políticos y Constitucionales "Lucas Mallada" y Academia General Militar, 1995; y Javier Alvarado PlanAs y Regina M. ${ }^{a}$ PÉreZ MARCos (coordinadores), Estudios sobre ejército, política y derecho en España (siglos XII-XX), ponencias del Curso de verano, Ávila, 10-16 julio 1995, Madrid, Polifemo, 1996. 
das en nuestro Estado Social y Democrático de Derecho y sentar la reserva de ley orgánica en la organización militar, pero hay muchos más. Así, tenemos el artículo 15, que declara abolida la pena de muerte "salvo lo que puedan disponer las leyes penales militares para tiempos de guerra"; el 22.5, que prohíbe las asociaciones "de carácter paramilitar", además de las secretas; el 25.3, que prohíbe a la Administración civil, no a la militar, imponer "sanciones que, directa o subsidiariamente, impliquen privación de libertad"; el 26, que prohíbe la existencia de "Tribunales de Honor en el ámbito de la Administración civil», y no de la militar; el 28.1, que permite al legislador "limitar o exceptuar» el ejercicio de la libertad sindical a las Fuerzas o Institutos armados y a los demás Cuerpos sometidos a disciplina militar»; el 29, que establece que los miembros de estas mismas instituciones solo podrán ejercer el derecho de petición «individualmente y con arreglo a lo dispuesto en su disposición específica»; el 30, que sienta el derecho-deber de los españoles "de defender a España" y ordena a la ley fijar "las obligaciones militares de los españoles" y regular la objeción de conciencia y las demás causas de exención del servicio militar obligatorio; el 62, que en sus apartados f) y h) atribuye al Rey "conferir los empleos civiles y militares" y "ejercer el mando supremo de las Fuerzas Armadas»; el 65.2, que atribuye al Rey la facultad de nombrar y relevar libremente "a los miembros civiles y militares de su Casa"; el 70.1, que, en su apartado f) declara inelegibles a "los militares profesionales y miembros de las Fuerzas y Cuerpos de Seguridad y Policía en activo"; el 94.1.b), que requiere la previa autorización de las Cortes en la prestación del consentimiento del Estado para obligarse por medio de "tratados o convenios de carácter militar»; el 97, que atribuye al Gobierno la dirección de "la política interior y exterior, la Administración civil y militar y la defensa del Estado"; el 117.5, que ordena al legislador regular "el ejercicio de la jurisdicción militar en el ámbito estrictamente castrense y en los supuestos de estado de sitio"; y el 149.1.4 ${ }^{\circ}$, que atribuye al Estado competencia exclusiva sobre "defensa y Fuerzas Armadas» ${ }^{3}$.

A la vista de este impresionante elenco normativo, y haciendo uso de una perspectiva analítico-sistemática, se puede decir que la relación entre el Derecho Constitucional y las Fuerzas Armadas se despliega en cinco grandes zonas materiales: la función de las Fuerzas Armadas en nuestro Estado, la participación y colaboración de los ciudadanos en las

3 Además de estos artículos, cabría citar el artículo 63, que atribuye al Rey la facultad, previa autorización de las Cortes Generales, de «declarar la guerra y hacer la paz", así como los artículos 55.1 y 116, en donde se trata de la declaración y efectos de los estados de alarma, excepción y sitio, situaciones todas ellas en que las Fuerzas Armadas pueden tener un relevante papel. 
mismas, las limitaciones que el ordenamiento establece en el disfrute y ejercicio de los derechos fundamentales por parte de sus miembros, el mando y organización básica de esta institución y las peculiaridades que la misma presenta en la estructura y funcionamiento del Estado 4 .

No es, sin embargo, de ninguno de estos temas de lo que queremos ocuparnos a continuación. Preferimos centrar nuestra atención en una zona menos visible y llamativa de la relación entre las Fuerzas Armadas y el Derecho Constitucional, por no estar expresamente trazada en la Constitución, pero que presenta un gran interés jurídico-político. Nos referimos a las limitaciones materiales que de forma indirecta sufren los miembros de las Fuerzas Armadas en relación con el ejercicio de sus derechos fundamentales; son restricciones que derivan de su condición militar, pero que no tienen anclaje en la Constitución, es decir, que no están previstas expresa o tácitamente en la Constitución, ni son queridas por ella, sino, más bien, todo lo contrario: su remoción por el legislador es una exigencia constitucional (artículo 9.2 CE).

Estas limitaciones afectan a casi todos los derechos fundamentales, como es el caso, por ejemplo, del derecho de sufragio, la libertad religiosa, la tutela judicial efectiva, el libre desarrollo de la personalidad, la protección de la familia o la promoción profesional. No obstante, no es nuestra intención, por evidentes motivos de oportunidad y espacio, estudiar ahora en su conjunto esta compleja problemática y examinar el estado de cada uno de los derechos fundamentales, sino centrarme en uno de ellos y, más en concreto, en alguna de sus manifestaciones más significativas y relevantes.

4 Todos estos temas han sido tratados por la doctrina, con mayor o menor detenimiento, y con gran tino, por cierto, en la mayoría de las ocasiones. La materia que más ha merecido la atención de los especialistas ha sido, desde luego, la de las restricciones que el ordenamiento jurídico impone al personal de las Fuerzas Armadas en relación con el ejercicio de sus derechos fundamentales. En este sentido vid., entre otros, Luis PRIETO y Carlos BruquetAs (ed.), Libertades públicas y fuerzas armadas, Actas de las jornadas de estudio celebradas en el Instituto de Derechos Humanos de la Universidad Complutense, Madrid, 4-24 febrero, 1984, Madrid, Ministerio de Educación y Ciencia, 1985; Luis PRIETO (ed.), Libertades públicas y fuerzas armadas, Madrid, Ministerio de Educación y Ciencia, 1986; Lorenzo Cotino HuESO, La singularidad militar y el principio de igualdad. Las posibilidades de este binomio ante las Fuerzas Armadas del siglo XXI, Madrid, Centro de Estudios Políticos y Constitucionales, 2000; Juan José HERBÓN COSTAS, "Libertad ideológica y religiosa en las Fuerzas Armadas", en Revista Española de Derecho Militar, n. ${ }^{\circ}$ 82, 2003, pp. 235262; y Fabio PASCUAL MATEO, "Reflexiones en torno al derecho de asociación de los miembros de las Fuerzas Armadas y de la Guardia Civil», en Revista de Administración Pública, n. ${ }^{\circ}$ 160, 2003, pp. 361-398. 
De acuerdo con estas intenciones, hemos escogido como tema de estudio el ejercicio del derecho de sufragio por parte de los miembros de las Fuerzas Armadas, lo que se traduce, básicamente, dado el estado de la legislación, en el examen del procedimiento especial de votación previsto en la actualidad para los miembros de este colectivo destacados en el exterior. Nos hemos inclinado por este tema porque nos parece que es paradigmático y tiene una enorme relevancia, en cuanto que el ejercicio del sufragio contribuye decisivamente a la plena realización ciudadana de los militares, además de estar sin tratar por parte de la doctrina ${ }^{5}$.

Abordaremos su estudio de acuerdo con el siguiente esquema: en primer lugar, se procede a situar al procedimiento en su contexto histórico y normativo; a continuación, se determinan las especialidades que presenta respecto del común u ordinario; en tercer término, se pasa a delimitar el ámbito de aplicación del procedimiento; seguidamente nos ocupamos de analizar los diversos trámites que componen el mismo; y, por último, nos detenemos en unas propuestas concretas de modificación normativa de cara a su mejor y más coherente funcionamiento.

Antes de ello, queremos poner de manifiesto que nuestro interés por esta materia viene dado por la constatación del desequilibrio que existe en la relación entre la sociedad y las Fuerzas Armadas. Creemos que a las Fuerzas Armadas y a sus integrantes se les ha exigido en el pasado y se les exige en la actualidad esfuerzos y sacrificios de todo tipo, pero que se les ha dado y se les da muy poco a cambio ${ }^{6}$. No es éste el lugar,

5 Hay otros temas que se insertan es esta temática y que tienen también un indudable interés, pero que han merecido mayor atención por parte de la doctrina. EI caso paradigmático es el de la libertad religiosa. En relación con el mismo vid., por ejemplo, José María CONTRERAS MAZARIO, El régimen jurídico de la asistencia religiosa a las Fuerzas Armadas en el sistema español, Madrid, Ministerio de Justicia, 1989; Juan José HeRbón Costas, "Libertad ideológica...", op. cit.; M. a Reyes León BEníteZ, "Multiculturalidad y asistencia religiosa a las fuerzas armadas españolas", en $R e-$ vista General de Derecho, n. ${ }^{\circ} 2,2004$, pp. 1 y ss.; José Luis MARTín DELPón, "Libertad religiosa y Fuerzas Armadas", en Revista Española de Derecho Canónico, n. ${ }^{\circ} 159$, 2005, pp. 587-622; y María MoREno ANTón, El principio de igualdad en la asistencia religiosa a las Fuerzas Armadas, Salamanca, Salamanca, Universidad Pontificia, 1989.

6 Donde más ha hecho el Estado por las Fuerzas Armadas y su personal ha sido sin duda, hasta el momento, en materia de libertad religiosa. Ello tiene su origen en el secular régimen confesional español. La norma clave en la actualidad es, como es sabido, el Acuerdo entre España y la Santa Sede de 3 de enero de 1979 sobre fuerzas armadas y servicio militar de clérigos y religiosos, que es uno de los cuatro Acuerdos firmados en esa fecha. 
desde luego, de hacer la lista de quejas y reclamaciones de los militares, pero sí de poner de manifiesto el problema y hacer algo al respecto. $\mathrm{Pa}$ rafraseando al célebre Presidente norteamericano, John F. Kennedy, podríamos decir que ha llegado el momento de poner de relieve no sólo lo que las Fuerzas Armadas pueden hacer por la sociedad, sino también lo que la sociedad puede hacer por las Fuerzas Armadas.

\section{REGULACIÓN}

\section{A) Marco normativo}

El procedimiento de votación del personal perteneciente a unidades militares destacadas fuera del territorio nacional es uno de los diversos procedimientos de emisión del voto previstos en nuestro ordenamiento jurídico; más en concreto, es uno de los cinco procedimientos especiales de voto a distancia actualmente regulados en el Derecho español. Conviene aclarar lo que decimos de forma más detenida, a fin de poder valorar de forma correcta el alcance y significado de este procedimiento.

Desde este punto de vista más explicativo hay que señalar, en primer lugar, que en nuestro Derecho existen dos modalidades básicas de votación: el voto directo o emitido por el elector de forma personal en la urna y el voto a distancia, previsto para todos aquellos ciudadanos a los que les es imposible o muy difícil acercarse a las urnas; en segundo lugar, que dentro de cada una de estas modalidades de votación existe un procedimiento general u ordinario de emisión del voto y varios especiales destinados a determinados colectivos de electores; $y$, en tercer lugar, que en el caso del voto a distancia esos procedimientos especiales son cinco ${ }^{7}$ : el de los ciudadanos que acrediten sufrir enfermedad o incapacidad que les impida formular personalmente su solicitud de voto por correo; el de los electores residentes-ausentes en relación con las elecciones generales, autonómicas y europeas; el de este mismo colectivo pero respecto de las elecciones locales; el del personal embarcado en los buques de la Armada, de la Marina Mercante española o de la flota pesquera de altura que durante el período electoral toquen puerto en España; y, finalmente el del personal embarcado en bu-

7 En el terreno del voto directo los procedimientos especiales son dos: el procedimiento de los analfabetos e impedidos para realizar por sí mismos las operaciones electorales de confección y entrega del voto al Presidente y el de los interventores y miembros de las Mesas Electorales. 
ques de la Armada o perteneciente a unidades militares terrestres o aéreas que se encuentre destacado en el exterior ${ }^{8}$.

El poder público, por tanto, consciente de las diferentes situaciones en que pueden encontrarse los ciudadanos a la hora de acercarse a las urnas, ha estimado conveniente permitir tanto el voto directo como el voto a distancia, así como admitir también que tanto en un caso como en el otro existan especialidades o singularidades en la tramitación del voto de determinados colectivos. El objetivo que se persigue con ello es, evidentemente, facilitar el ejercicio del derecho de sufragio, lo que entra de lleno en el terreno de la labor promocional de la participación política que deben llevar a cabo los poderes públicos ex articulo 9.2 CE9.

Todos estos procedimientos están previstos y regulados en distintas normas, de muy diferente rango. En primer lugar, y como es natural, en la Ley Orgánica 5/1985, de 19 de junio, del Régimen Electoral General (en adelante LOREG), pero también en muchas otras disposiciones complementarias: el Real Decreto 605/1999, de 16 de abril, de regulación complementaria de los procesos electorales; el Real Decreto $557 / 1993$, de 16 de abril, sobre actuación notarial en el procedimiento de emisión del voto por correo; la Orden del Ministerio de Defensa 116/1999, de 30 de abril, por la que se regula el ejercicio del derecho al voto en los procesos electorales del personal de las Fuerzas Armadas embarcado o en situaciones excepcionales vinculadas con la defensa nacional ; la Orden que el Ministerio de Fomento dicta en cada proceso electoral para regular la colaboración del Servicio de Correos en el mismo, pues siempre contiene referencias al voto por correo ${ }^{10} ; \mathrm{y}$, por último, las diversas Instrucciones aprobadas hasta la fecha por la Junta Electoral Central ${ }^{11}$.

8 En relación con el voto a distancia en general vid. Luis GÁLVEZ MUÑOZ, «El voto por correo: ¿una nueva reforma?», en Revista de Derecho Político, núm. 52, 2001, pp. 249-308.

9 Sobre este principio de facilitación del sufragio vid. Luis GÁlVEZ MUÑOZ, «EI voto...", op. cit., pp. 257 y ss.

${ }^{10}$ La última orden que ha dictado el Ministerio de Fomento en esta materia es la 870/2007, de 4 de abril, por la que se dictan normas sobre la colaboración del servicio de correos en las elecciones autonómicas, locales y a las Asambleas de Ceuta y Melilla y otros procesos electorales (BOE 82/2007, de 5 de abril).

11 Vid. la Instrucción de la Junta Electoral Central de 26 de abril de 1993 sobre la comprobación por la Junta Electoral competente de la concurrencia de las circunstancias a que se refiere el artículo 72-c LOREG; la de 26 de abril de 1993 sobre emisión del certificado médico oficial y gratuito a que se refiere el artículo 72-c LOREG; o la de 20 de abril de 1998 sobre requisitos del voto de los electores inscritos en el Censo Especial de Residentes Ausentes. 


\section{B) Regulación actual y antecedentes históricos}

El procedimiento especial de votación del personal de las Fuerzas Armadas en el exterior, que es el único que nos interesa ahora por ser precisamente el objeto de este trabajo, se encuentra regulado en la Orden Ministerial 116/1999, de 30 de abril ${ }^{12}$, la cual ha sido dictada por el Ministro de Defensa en ejercicio de la habilitación normativa concedida de forma expresa para ello por la Disposición Adicional Tercera del Real Decreto 605/1999, de 16 de abril, de regulación complementaria de los procesos electores. El texto de esta Disposición habilitadora dice así:

«Por el Ministerio de Defensa se podrán dictar las normas que resulten necesarias para la adaptación de lo previsto en el artículo 9 del presente Real Decreto al personal embarcado en buques de la Armada, cuando se encuentren en situaciones excepcionales, vinculadas con la Defensa Nacional, que así lo aconsejen. En dichas normas podrán incluirse, asimismo, las previsiones oportunas para asegurar el ejercicio del derecho al sufragio, mediante el voto por correo, del personal perteneciente a unidades militares terrestres o aéreas que se encuentre destacado fuera del territorio nacional, en las precitadas situaciones excepcionales, y que participe o coopere con las Fuerzas de los países aliados y de Organizaciones internacionales en misiones de asistencia humanitaria o de mantenimiento de la paz internacional».

Esta Disposición Adicional habilitadora del Real Decreto 605/1999, de 16 de abril, se sustenta, a su vez, en dos disposiciones concretas de la LOREG que es conveniente mencionar. En primer lugar se apoya, aunque de forma parcial, en el artículo 74 de la LOREG, el cual ordena al Gobierno regular las especialidades para el voto por correo "del personal embarcado en buques de la Armada", además del que se haIle en buques de la Marina Mercante española y de la flota pesquera ${ }^{13}$. $Y$, en segundo término, se ampara también, como es común a todas las normas reglamentarias estatales de carácter electoral, en la Disposición Adicional Segunda de la LOREG, que faculta genéricamente al Gobierno "para dictar cuantas disposiciones sean precisas para el cumplimiento y ejecución de la presente Ley".

12 Orden del Ministerio de Defensa 116/1999, de 30 de abril, por la que se regula el ejercicio del derecho al voto en los procesos electorales del personal de las Fuerzas Armadas embarcado o en situaciones excepcionales vinculadas con la defensa nacional (BOE núm. 106/1999, de 4 de mayo, p. 16273).

${ }^{13}$ En este artículo se sustenta también, y de forma plena, el procedimiento previsto en el artículo 9 del Real Decreto 605/1999, de 16 de abril, de regulación complementaria de los procesos electorales, para el personal embarcado en general, y no solo el que se halle en buques de la Armada, durante el período electoral. 
La Orden Ministerial 116/1999, de 30 de abril, es, como ya hemos dicho, la norma que regula en la actualidad el procedimiento de votación a distancia de los militares que se encuentren fuera del país, pero no es la única norma que lo ha hecho hasta el momento. Con anterioridad se ocupó de este procedimiento, y en términos prácticamente idénticos, la Orden Ministerial 53/1993, de 11 de mayo ${ }^{14}$, dictada en desarrollo de la Disposición Adicional Segunda del Real Decreto 421/1991, de 5 de abril, ya derogado, por el que se dictaban normas reguladoras de los procesos electorales ${ }^{15}$.

Los antecedentes normativos de este procedimiento de votación no acaban aquí, pues todavía cabe citar una Orden ministerial de 28 de septiembre de 1990, la cual contenía una regulación procedimental muy parecida a la actual. Su alcance era, sin embargo, mucho más limitado, puesto que, entre otras cosas, sólo mencionaba al personal embarcado en buques de la Armada que participara en misiones de paz y no al perteneciente a unidades terrestres o aéreas o al embarcado en otro tipo de situaciones excepcionales ${ }^{16}$.

Mas allá de 1990 no hay antecedentes en nuestro ordenamiento electoral del procedimiento que estudiamos, lo cual no debe interpretarse como dejación de funciones por parte del legislador. Hay que tener presente, por un lado, la existencia desde 1977 del procedimiento especial de votación a distancia para el personal embarcado que durante el período electoral "toque puertos, previamente conocidos, en el territorio nacional", en el que se incluye al personal a bordo de buques de la Armada; y, por otro lado, y sobre todo, la reducida actividad que nuestras Fuerzas Armadas han desarrollado fuera de las fronteras nacionales hasta hace muy poco tiempo. Se puede decir que hasta la implicación, a finales de la década de los 80 del pasado siglo, de nues-

14 Orden del Ministerio de Defensa 53/1993, de 11 de mayo, por la que se regula el ejercicio del derecho al voto en los próximos procesos electorales del personal destinado en misiones de paz internacionales (BOE núm. 115/1993, de 14 de mayo).

15 Los términos de esta Disposición Adicional Segunda del Real Decreto 421/1991, de 5 de abril, son idénticos a los de la Disposición Adicional Tercera del Real Decreto 605/1999, de 16 de abril. No obstante, esto fue así únicamente a partir de la modificación efectuada en esa norma por el Real Decreto 563/1993, de 16 de abril. La redacción original de la Disposición Adicional Segunda sólo hablaba del "personal embarcado en buques de la Armada, cuando se encuentre en situaciones excepcionales, vinculadas con la Defensa Nacional».

16 Orden del Ministerio de Relaciones con las Cortes y de la Secretaria del Gobierno de 28 de septiembre de 1990 por la que se regula el ejercicio del derecho de voto por el personal embarcado en buques de la Armada, destinado en misiones de paz internacionales (BOE núm. 234/1990, de 29 de septiembre, p. 28346). 
tras Fuerzas Armadas en operaciones internacionales de mantenimiento de la paz, no se había evidenciado la necesidad de regular un procedimiento de votación específico para los militares españoles operantes en el exterior.

\section{LAS ESPECIALIDADES QUE PRESENTA}

\section{A) La vinculación con el procedimiento del personal embarcado}

Tras determinar la norma que regula el procedimiento especial de votación de los militares en el exterior y conocer sus apoyos normativos y sus antecedentes históricos, lo que procede ahora es realizar el estudio de su contenido. Y lo primero que hay que hacer en este terreno, por tratarse de un procedimiento especial, es, lógicamente, examinar las especialidades o singularidades que presenta respecto del procedimiento general u ordinario.

Así hay que hacerlo con todos los procedimientos especiales, aunque en este caso hay que advertir que la tarea alcanza mayor grado de complejidad. La razón estriba en que el procedimiento de los militares en el exterior se presenta formalmente como una variación del procedimiento especial del personal embarcado. La Disposición Adicional Tercera del Real Decreto 605/1999, de 16 de abril, de regulación complementaria de los procesos electorales, que como sabemos es el título habilitante de la Orden Ministerial que regula este procedimiento, lo deja muy claro al hablar expresamente de que el mismo supone "la adaptación de lo previsto en el artículo 9 del presente Real Decreto" a las circunstancias de los militares en situaciones excepcionales, siendo el artículo 9 que se cita el que se ocupa de regular el procedimiento especial del personal embarcado.

Con el procedimiento especial de los militares en el exterior se ha tratado, pues, de adaptar el procedimiento especial del personal embarcado a las peculiaridades que pueda presentar el ejercicio del derecho de voto por parte de los militares que se hallen fuera del territorio nacional cumpliendo determinadas misiones. Dichas peculiaridades vienen determinadas, básicamente, por la no previsión, en el momento de la convocatoria de las elecciones, de contacto directo con el territorio nacional durante el período electoral ${ }^{17}$.

17 En el procedimiento especial de voto a distancia del personal embarcado se exige, como requisito para su aplicación, que durante el período electoral dicho personal "toque puertos, previamente conocidos en el territorio nacional» (punto 1 del 
Nos encontramos así, desde la óptica del legislador, ante una variante del procedimiento especial del personal embarcado o, dicho de forma más expresiva, ante una especie de procedimiento especial del procedimiento especial del personal embarcado. $Y$ aunque luego las cosas no resulten en la realidad normativa exactamente así, como tendremos ocasión de comprobar enseguida, hay que reconocer, cuando menos, que se trata de dos procedimientos estrechamente relacionados.

\section{B) Las especialidades en particular}

Advertida la peculiar posición o naturaleza que tiene el procedimiento de los militares en el exterior -aunque, como acabamos de apuntar, más en las intenciones que en la realidad-, hay que determinar ya, sin más demora, cuáles son las especialidades que presenta, y ello tanto frente al procedimiento ordinario como frente al procedimiento especial del personal embarcado. Tomaremos como hilo conductor las singularidades que resultan de la comparación entre el procedimiento que estudiamos y el procedimiento ordinario, dejando constancia a cada paso de las diferencias que se observen también con el procedimiento del personal embarcado.

De acuerdo con este plan expositivo hay que decir que son seis las especialidades que el procedimiento de los militares en situaciones excepcionales presenta en relación con el procedimiento ordinario. Se trata de las siguientes:

a) La consideración de los servicios de radiotelegrafía de los buques de la Armada y de las unidades militares terrestres y aéreas como "dependencias delegadas del Servicio de Correos", a los efectos de presentación y remisión de la solicitud de la certificación censal y demás documentos electorales precisos para votar a distancia ${ }^{18}$. Así sucede también en el procedimiento del personal embarcado, aunque li-

artículo 9 del Real Decreto 605/1999, de 16 de abril, de regulación complementaria de los procesos electores).

${ }^{18}$ Esta habilitación legal la realiza el artículo 6 de la Orden del Ministerio de Defensa 116/1999, de 30 de abril, cuyo texto dice así: "A los efectos previstos en los párrafos a) y b) del art. 72 de la Ley Orgánica del Régimen Electoral General, los servicios de radiotelegrafía de los buques o de las Unidades tendrán la consideración de dependencias delegadas del Servicio de Correos, y los Comandantes de buque o Jefes de Unidad o el Oficial en el que expresamente deleguen, así como el Comandante del avión-estafeta y el Director general de Personal del Ministerio de Defensa, la de funcionarios encargados de la recepción de la solicitud". 
mitado en este caso, lógicamente, a los servicios de radiotelegrafía de los buques.

b) Igualmente, la consideración de los Comandantes de buque o Jefes de Unidad, o el Oficial en el que éstos expresamente deleguen, así como de los Comandantes de los aviones-estafeta y del Director General de Personal del Ministerio de Defensa, como "funcionarios encargados de la recepción de la solicitud" que hagan los militares en orden a la obtención del certificado censal y demás documentación electoral ${ }^{19}$. En el procedimiento del personal embarcado los sujetos habilitados son sólo los Comandantes y Capitanes de los buques, o el oficial en el que éstos expresamente deleguen, sin hacerse referencia alguna a sujetos externos a la unidad.

Los tres tipos de sujetos habilitados en este procedimiento como "funcionarios encargados de la recepción de la solicitud" tienen, sin embargo, papeles distintos: los Comandantes de buque o Jefes de Unidad, o el Oficial en el que expresamente deleguen, son quienes reciben materialmente las solicitudes; los Comandantes de los avionesestafeta son los que deben recoger, en su caso $^{20}$, las solicitudes presentadas ante los anteriores y encargarse de su traslado a España; y el Director General de Personal del Ministerio de Defensa es la persona a la que los Comandantes de buque o Jefes de Unidad deben remitir las solicitudes, bien por radiotelegrafía, bien por medio de un avión-estafeta, para su posterior envío a las Delegaciones Provinciales de la Oficina del Censo Electoral (en adelante, OCE).

c) El establecimiento de un intermediario entre los Comandantes de buque o Jefes de Unidad, que son quienes reciben las solicitudes de voto a distancia, y las correspondientes Delegaciones Provinciales de la $\mathrm{OCE}$, que son las que las tramitan. Este intermediario, que no existe en el procedimiento del personal embarcado, es el Director General de Personal del Ministerio de Defensa. Es él quien recibe las solicitudes presentadas ante los distintos Comandantes de buque y Jefes de Unidad y las trasmite a las Delegaciones Provinciales de la OCE; y es él también quien recibe de estas Delegaciones las contestaciones conte-

19 Vid. el texto del artículo 7 de la Orden 116/1999, de 30 de abril, trascrito en la nota anterior.

20 La referencia al Comandante del avión-estafeta como "funcionario encargado de la recepción de la solicitud" solo tiene sentido si se admite la posibilidad, no mencionada expresamente en la Orden 116/1999, de 30 de abril, de que los Comandantes de buque o Jefes de Unidad, o el Oficial en el que expresamente deleguen, puedan remitir las solicitudes no solo por radiotelegrafía, sino también por medio de los aviones-estafeta. 
niendo la documentación precisa para votar y las remite a los respectivos Comandantes de buque y Jefes de Unidad para su posterior traslado a los electores ${ }^{21}$.

d) El establecimiento, también de forma novedosa respecto al procedimiento del personal embarcado, de intermediarios entre el elector que ha ejercido su voto y el Servicio de Correos que ha de entregarlo en la Mesa Electoral de destino. Los intermediarios son tres: el Comandante del buque o Jefe de Unidad, a quien el elector entrega el sobre electoral para su custodia; el Comandante del avión-estafeta, que es quien traslada bajo su responsabilidad los sobres a España; y el Director General de Personal del Ministerio de Defensa, que es el que se encarga de hacer llegar los votos que se reciban de las unidades militares al organismo autónomo de Correos ${ }^{22}$.

e) El empleo, además del correo postal, de otros medios de comunicación y transporte en orden a hacer posible el voto a distancia de los militares en el exterior. Así, el Comandante del buque o Jefe de Unidad en donde se hallen los electores puede enviar las solicitudes de certificación censal y demás documentación electoral por "radiotelegrafía" o por medio del "avión-estafeta» ${ }^{23}$; el Director General de Personal del Ministerio de Defensa debe hacer llegar la documentación electoral al elector "por el medio más urgente posible», sin indicarse cuál; el Comandante del buque o Jefe de Unidad ha de entregar los votos emitidos al Comandante del "avión-estafeta" para su traslado a la península; y el Director General de Personal del Ministerio de Defensa "hará llegar», sin especificarse cómo, los votos recibidos al Servicio de Correos ${ }^{24}$.

Este es un elemento parcialmente común con el procedimiento especial del personal embarcado. No obstante, en este último procedimiento el empleo de medios alternativos al correo es mucho más limitado, ya que sólo está previsto el uso de la radiotelegrafía para cursar las solicitudes ${ }^{25}$. Con todo, los proyectos de reforma del mismo apuntan a una aproximación en este punto entre ambos procedimientos ${ }^{26}$.

21 Vid. Ios artículos 3 y 4 de la Orden 116/1999, de 30 de abril.

22 Vid. el artículo 5 de la Orden 116/1999, de 30 de abril.

${ }^{23}$ Esto no lo dice expresamente el artículo 3 de la Orden 116/1999, de 30 de abril, dedicado al envío de las solicitudes de los electores, pero se deduce de una lectura conjunta de este artículo y del artículo 7.

24 Vid. Ios artículos 4 y 5 de la Orden 116/1999, de 30 de abril.

25 Vid. el artículo 9.2 del Real Decreto 605/1999, de 16 de abril, de regulación complementaria de los procesos electores.

${ }_{26}$ Vid. el Boletín Oficial de las Cortes Generales, Senado, Serie I, núm. 439, de 30 de mayo de 2003, en el que se contiene una interesante referencia a un proyecto 
f) La eliminación de toda referencia a la determinación del lugar al que la Delegación Provincial de la OCE ha de remitir al elector la documentación electoral. En el procedimiento ordinario ${ }^{27}$ y en el del personal embarcado se establecían reglas concretas en esta materia ${ }^{28}$, pero ahora no se indica nada, por considerarse, seguramente, que el lugar natural de recepción de dicha documentación es el buque o unidad militar terrestre o aérea en la que el solicitante se halle destinado.

\section{IV) ÁMBITO DE APLICACIÓN}

\section{A) La dificultad de su delimitación}

Conocidas las especialidades que presenta el procedimiento de los militares destacados en el exterior, lo que procede, a continuación, es delimitar o concretar su ámbito de aplicación. Es esta una tarea que presenta cierto grado de complejidad, aunque no tanta como en el procedimiento del personal embarcado, con el que, como acabamos de ver, el procedimiento que estamos estudiando está tan relacionado. En cualquier caso, reviste más complejidad de la deseable.

En este cometido parece oportuno tomar como punto de partida los dos artículos que la Orden 116/1999, de 30 de abril, dedica a esta cuestión. Se trata, en primer lugar, del artículo 2, que establece que «el procedimiento será de aplicación a todo el personal que se encuentre en la situación descrita en el punto primero desde la fecha de convocatoria de las elecciones hasta su celebración"; y, en segundo término, del artículo 1, en el que se describe dicha situación y cuyo texto dice así:

de modificación del artículo 9 (procedimiento especial del personal embarcado) del Real Decreto 605/1999, de 16 de abril, de regulación complementaria de los procesos electores.

27 En el procedimiento ordinario de voto a distancia el artículo 73.2 de la LOREG reconoce el derecho de los electores a designar el domicilio al que la Delegación Provincial de la OCE tiene que remitirle la documentación electoral, estableciendo, además, como regla subsidiaria, que si no señala ninguno, se le enviará al domicilio que figure en el censo.

${ }^{28}$ En el procedimiento especial del personal embarcado el elector tiene dos posibilidades a la hora de designar el lugar de remisión de la documentación electoral: bien el puerto o puertos en que esté prevista la arribada del buque de embarque, bien, en caso de ser posible la entrega por medio de otro buque, la sede del armador o consignatario o el puerto en que se halle dicho buque (párrafos segundo y tercero del artículo 9 del Real Decreto 605/1999, de 16 de abril). 
«Para el ejercicio del derecho de voto por correo del personal embarcado en buques de la Armada o que, perteneciendo a unidades militares terrestres o aéreas, se encuentre destacado fuera del territorio nacional, en situaciones excepcionales, vinculadas con la defensa nacional y que participe o coopere, con las Fuerzas de los países aliados y de organizaciones internacionales, en misiones de asistencia humanitaria o mantenimiento de la paz internacional, se seguirá el procedimiento establecido en los puntos siguientes de la presente Orden ${ }^{29}$.

La lectura de estos artículos deja cierta sensación de inconcreción en relación con el ámbito de aplicación del procedimiento. Así, por ejemplo, no se sabe muy bien qué condiciones de las citadas en el artículo 1 (estar destacado fuera del territorio nacional, hallarse en situaciones excepcionales, participar o cooperar en misiones internacionales) se aplican al personal embarcado en buques de la Armada y cuáles al perteneciente a unidades militares marítimas y aéreas, o si todas las condiciones citadas son aplicables a unos y otros sujetos.

Para despejar las dudas planteadas se hace preciso acudir a los criterios generales de la interpretación jurídica y, en función de ellos, a materiales concretos como el texto de la habilitación normativa en que se apoya la Orden Ministerial que regula este procedimiento (Disposición Transitoria Tercera del Real Decreto 605/1999, de 16 de abril), la Exposición de Motivos de ésta ${ }^{30}$, las normas que en el pasado se han ocupado de disciplinar el procedimiento (Orden 53/1993, de 14 de mayo, y Orden de 28 de septiembre de 1990) ${ }^{31}$, los artículos 72 y 73 de

${ }^{29}$ El texto de este artículo 1 es idéntico, partícula a partícula, al del artículo 1 de la Orden 53/1993, de 12 de abril, que regulaba anteriormente este procedimiento. La novedad se encuentra en el artículo 2, pues la normativa anterior no contenía referencia alguna a lo recogido en el mismo.

30 La Exposición de Motivos de la Orden 116/1999, de 30 de abril, reguladora de este procedimiento es muy reducida, pues se limita a señalar en un único párrafo la conveniencia de su establecimiento. No obstante, el párrafo en cuestión es muy significativo, al expresar muy claramente la finalidad principal del procedimiento: "La situación excepcional en la que se encuentra el personal de las Fuerzas Armadas, destacado fuera del territorio nacional, participando o cooperando en misiones de asistencia humanitaria o de mantenimiento de la paz internacional, aconseja dictar normas especiales para garantizar el ejercicio del derecho de sufragio por las dotaciones correspondientes.

31 De la Orden 53/1993, de 14 de mayo, ya derogada, hay que destacar su Exposición de Motivos: "La situación excepcional en la que se encuentran buques de la Armada que participan en misiones de paz internacionales y personal perteneciente a Unidades Militares Terrestres o Aéreas, que se encuentre destacado fuera del territorio nacional, en las precitadas situaciones excepcionales, y que participe o coopere con las Fuerzas de los países aliados y de Organizaciones Internacionales 
la LOREG que regulan el procedimiento ordinario de votación a distancia y el artículo 9 del Real Decreto 605/1999, de 16 de abril, dedicado al procedimiento del personal embarcado. No es un auxilio seguro, pero puede ayudar bastante a clarificar la situación.

\section{B) Requisitos para la aplicación del procedimiento}

De acuerdo con ello, es posible descubrir tres requisitos de distinta naturaleza en los artículos 1 y 2 de la Orden Ministerial. Son los requisitos cuya concurrencia permite proceder a la aplicación del procedimiento que estudiamos. Vamos a enumerarlos.

a) En primer lugar, un requisito de carácter local o espacial. El procedimiento en cuestión se aplica a todas aquellas personas que se encuentren embarcadas en buques de la Armada o que pertenezcan a unidades militares terrestres o aéreas destacadas fuera del territorio nacional.

La redacción del artículo 1 de la Orden 116/1999, de 30 de abril, no permite saber con claridad si la alusión a encontrarse destacado fuera del territorio nacional se aplica tanto buques de la Armada como a las unidades militares terrestres o aéreas, o únicamente a estas ${ }^{32}$, pero la lectura de la Disposición Transitoria Tercera del Real Decreto 605/1999, de 16 de abril, aclara en buena parte las dudas, inclinándonos por la solución menos restrictiva, al aludir diferenciadamente a los dos tipos de destacamentos y mencionar la exigencia de encontrarse fuera del territorio nacional únicamente para las unidades de tierra y aire. Lo relevante, por tanto, en un caso sería estar embarcado y en el otro estar en una unidad que se halla fuera del territorio nacional.

No obstante, si reflexionamos un poco y pasamos de una visión formal o gramatical del procedimiento a otra material, llegaremos rápidamente a la conclusión de que esta discusión carece de toda relevancia práctica, pues el estar embarcado ya lleva implícito estar destacado fuera del territorio nacional, en el sentido original de tierra

en misiones de asistencia humanitaria o de mantenimiento de la paz internacional, aconseja dictar normas especiales para garantizar el ejercicio del derecho de sufragio por las dotaciones correspondientes".

32 Recordemos que en este artículo 1 de la Orden 116/1999, de 30 de abril, se habla "del personal embarcado en buques de la Armada o que, perteneciendo a unidades militares terrestres o aéreas, se encuentre destacado fuera del territorio nacional, en situaciones excepcionales...". 
firme bajo jurisdicción española. $Y$ aunque fuera procedente dar una definición más técnica y amplia de "territorio nacional»" ${ }^{33}$, hay decir que, incluso en este caso, sería extremadamente raro, por no decir imposible, que la tripulación de un buque de la Armada permaneciera en las aguas jurisdiccionales españolas durante todo el período electoral, sin tocar tierra y sin estar previsto tampoco salir de tales aguas jurisdiccionales para desarrollar labores vinculadas a la defensa nacional o de participación en misiones internacionales de paz o asistencia humanitaria.

Adviértase, por último, para despejar cualquier posible duda, que de quien se predica estar destacado fuera del territorio español es, a la vez, tanto de las unidades militares terrestres o aéreas como de sus integrantes. Esto excluye, como es lógico, la posibilidad de utilizar el procedimiento de forma individualiza por un militar español concreto que se encontrara en misión oficial en el extranjero, permaneciendo su unidad en España, o al contrario, estando este militar en España y su unidad en el exterior. Lo importante es estar en el exterior y en una unidad militar en el exterior. El requisito local o espacial opera, pues, doblemente.

b) A este requisito debe añadirse, en segundo término, otro de naturaleza funcional. Es preciso que las personas citadas - las que se encuentran embarcadas en buques de la Armada o las que pertenezcan a unidades militares terrestres o aéreas destacadas fuera del territorio nacional- se hallen, además, en situaciones excepcionales vinculadas con la defensa nacional o con la participación o cooperación, con las Fuerzas de los países aliados o de organizaciones internacionales, en misiones de asistencia humanitaria o de mantenimiento de la paz internacional.

No está nada claro, dada la farragosa redacción del artículo 1 de la Orden Ministerial 116/1999, de 30 de abril, si este requisito debe aplicarse únicamente al personal perteneciente a unidades militares terrestres o aéreas o también al que se halla embarcado en buques de la Armada. La interpretación literal o gramatical del artículo 1 parece inclinarse por lo primero, pero la Exposición de Motivos de dicha norma, los antecedentes históricos, el examen del procedimiento ordinario y el

33 De acuerdo con el Derecho Internacional, el territorio de los Estados está constituido, como es sabido, por la tierra firme y las aguas lacustres y fluviales, el mar territorial — que está compuesto por la franja de agua marina próxima a la costa (actualmente 12 millas)—, el espacio aéreo que sobrevuela los espacios anteriores y el subsuelo bajo los mismo espacios. 
del personal embarcado, así como la habilitación normativa en que se apoya la Orden Ministerial (Disposición Adicional Tercera del Real Decreto 605/1999, de 16 de abril), conducen a la solución contraria, que es, precisamente, la que hemos adoptado aquí.

No obstante, lo más criticable no es esta indefinición, sino la existencia misma de este requisito. Son varios los argumentos en su contra. En primer lugar, ¿qué añade esta exigencia a los requisitos espacial y temporal? ¿Qué otra cosa sino actividades relativas a la defensa nacional o a la participación o cooperación, con las Fuerzas de los países aliados o de organizaciones internacionales, en misiones de asistencia humanitaria o de mantenimiento de la paz internacional, va a realizar, por ejemplo, una unidad militar terrestre desplazada a otro país durante varias semanas? ${ }^{34}$

Los supuestos de unidades militares en el exterior -marítimas, terrestres o aéreas- sin hallarse en las situaciones excepcionales descritas son, ciertamente, de muy difícil hallazgo. En nuestra opinión, siempre sería posible encontrar una conexión, más o menos remota, con la defensa nacional o con la cooperación aliada o internacional en misiones de asistencia humanitaria o de mantenimiento de la paz. Piénsese, por ejemplo, en el caso de la intervención de fuerzas españolas en un país en guerra para evacuar a ciudadanos españoles; si analizamos los antecedentes habidos siempre encontramos que esta intervención humanitaria se produce en un contexto de cooperación con los países aliados, la ONU u otras organizaciones internacionales ${ }^{35}$.

Y si esto es así, ¿para qué sirve exigir, como requisito extra, que el personal embarcado en buques de la Armada durante el período electoral o perteneciente a unidades militares terrestres o aéreas destacadas fuera del territorio nacional durante este mismo período, se encuentre, además, "en situaciones excepcionales vinculadas con la defensa nacional o con la participación o cooperación, con las Fuerzas de los países aliados o de organizaciones internacionales, en misiones de asistencia humanitaria o de mantenimiento de la paz internacional»?

Este argumento nos parece muy relevante, pero no definitivo. Es necesario completar la crítica con un segundo argumento. Se trata de po-

${ }^{34}$ Sobre las misiones de las Fuerzas Armadas y el tipo de operaciones que pueden llevar a cabo vid., además, del artículo 8 de la CE, los artículos 15 y 16 de la Ley Orgánica 5/2005, de 17 de noviembre, de la Defensa Nacional.

35 Más problemas de conexión puede haber en otros supuestos, como, por ejemplo, el del buque-escuela "Juan Sebastián Elcano». 
ner de manifiesto que aunque la realidad no fuera tal y como la acabamos de exponer, el requisito en cuestión sería, de todas formas, rechazable, a nuestro juicio, por enteramente gratuito, es decir, por no perseguir ninguna finalidad constitucionalmente legítima o, dicho de otro modo, que sea razonable desde el punto de vista constitucional. Por mucho que examinamos dicho requisito esta finalidad no aparece por ninguna parte.

Así pues, en el caso de que se aceptara que el personal embarcado en buques de la Armada o perteneciente a unidades militares terrestres o aéreas destacadas fuera del territorio nacional pudiera, en algunos casos, desarrollar labores no vinculadas con la defensa nacional ni con la participación o cooperación, con las Fuerzas de los países aliados o de organizaciones internacionales, en misiones de asistencia humanitaria o de mantenimiento de la paz internacional, no encontramos razón alguna para que el legislador desee dejar a estos electores fuera del procedimiento especial que estudiamos ${ }^{36}$.

Piénsese: ¿qué sentido tendría excluir a los militares en estos casos de las posibilidades de ejercicio del sufragio que otorga este procedimiento especial de votación a distancia?; ¿qué beneficio se obtiene con la restricción del ámbito de aplicación del procedimiento que implica la existencia de este requisito? Parece, a nuestro entender, que ninguno, por lo que hay que concluir que el requisito en cuestión resulta innecesario y digno de ser suprimido de la regulación.

c) La determinación del marco de aplicación se completa con un tercer requisito, ahora de carácter temporal. Para que el procedimiento pueda aplicarse es necesario que los requisitos anteriores -el espacial y el funcional- se mantengan durante determinado período de tiempo: el que va "desde la fecha de convocatoria de las elecciones hasta su celebración". Dicho de otra forma, es preciso que el personal que reúna las circunstancias de estar embarcado en un buque de la Armada o de pertenecer a una unidad militar terrestre o aérea destinada fuera del territorio nacional, y, en cualquier caso, la de hallarse en una situación excepcional vinculada con la defensa nacional o con la participación o cooperación en misiones de asistencia humanitaria o de mantenimiento

${ }^{36}$ Para lo único que podría servir este requisito es para diferenciar el ámbito de aplicación de este procedimiento respecto del que tienen el procedimiento del personal embarcado en general regulado en el artículo 9 del Real Decreto 605/1999. No obstante, como veremos luego, hay otras formas más eficaces de diferenciar ambos procedimiento y en cualquier caso, esto solo serviría para justificar el requisito respecto del personal embarcado en buques de la Armada y no para el personal de las unidades terrestre o aéreas. 
de la paz internacional, permanezca en dichas circunstancias durante el período electoral.

Este requisito debe interpretarse con flexibilidad. Así, no se puede exigir, para aplicar el procedimiento, que las personas que se hallen en la situación espacial y funcional descrita deban permanecer efectivamente en dicha situación durante todo el período electoral, sino que basta con que estén en ella, o con que sea previsible que estén en ella, durante el día de la votación y durante la parte del período electoral en que es legal y fácticamente posible tramitar el voto a distancia de forma ordinaria. En este sentido hay que tener en cuenta que, conforme a lo dispuesto en el procedimiento ordinario de voto a distancia, el plazo máximo para hacer la solicitud en orden a la obtención de documentación electoral acaba el décimo día anterior al de la votación y que, en cualquier caso, el procedimiento consta de numerosos trámites que llevan su tiempo ${ }^{37}$.

En definitiva, no creemos que fuera procedente excluir de la aplicación del procedimiento especial a un elector por el solo hecho de que se encuentre en España durante parte del período electoral. Lo importante es que no esté aquí durante el período en que puede votar de forma ordinaria, bien personalmente, bien a distancia.

\section{C) Algunas precisiones adicionales de interés}

Tras indicar los requisitos que, a nuestro juicio, establece la Orden Ministerial 116/1999, de 30 de abril, para poder proceder a la aplicación del procedimiento de votación a distancia en ella regulado, y precisar, al propio tiempo, y en la medida de lo posible, el alcance de cada uno de ellos, nos gustaría, a continuación, realizar varios comentarios adicionales. No nos detendremos, sin embargo, mucho en ellos, pues la pretensión que nos guía únicamente es la de remachar el cuadro general ya expuesto.

37 Así, el elector debe acudir a una oficina de Correos a cursar la solicitud de certificación de la inscripción en el censo electoral; el Servicio de Correos debe entregar esta solicitud a la correspondiente Delegación Provincial de la OCE; ésta debe examinar la procedencia de la solicitud, comprobar que el solicitante está efectivamente inscrito en el censo electoral, anotar en el censo que va a votar por correo, extender el certificado censal correspondiente, preparar el resto de la documentación electoral precisa para votar por correo y enviársela al elector; el Servicio de Correos debe entregar personalmente al elector dicha documentación; tras ello el elector debe emitir su voto y remitirlo por correo certificado desde una oficina de Correos. 
a) El primero de los comentarios a realizar hace referencia a la inexistencia de ningún requisito de carácter subjetivo en el elenco de exigencias determinantes de la aplicación del procedimiento en cuestión. Hemos aludido a un requisito espacial o local (personas que se encuentren embarcadas en buques de la Armada o que pertenezcan a unidades militares terrestres o aéreas destacadas fuera del territorio nacional), a otro de carácter funcional (hallarse en situaciones excepcionales vinculadas con la defensa nacional o con la participación o cooperación, con las Fuerzas de los países aliados o de organizaciones internacionales, en misiones de asistencia humanitaria o de mantenimiento de la paz internacional) y a un tercero de naturaleza temporal (permanecer en dichas circunstancias durante el período electoral), pero no hemos mencionado ninguno subjetivo, es decir, ninguno que aluda a la propia condición de la persona que lo utiliza o que es destinataria del mismo.

$Y$ esto ha sucedido no porque no hayamos pensado en esta posibilidad, sino por el hecho, más directo y científico, de haberla descartado motivadamente. Dicho de forma más clara y más concreta: nos hemos planteado la posibilidad de exigir la condición de militar o de miembro de las Fuerzas Armadas al elector que pretenda hacer uso de este procedimiento, pero no hemos encontrado ningún argumento de peso para hacerlo.

El argumento fundamental se encuentra en el primer nivel de la interpretación jurídica: ni el artículo 1 de la Orden Ministerial 116/1999, de 30 de abril, reguladora de este procedimiento, ni la Disposición Transitoria Tercera del Real Decreto 605/1999, de 16 de abril, que recoge la habilitación normativa para su regulación, exigen de forma expresa esta condición. En estas normas se alude al "personal embarcado en buques de la Armada" y al "perteneciente a unidades militares terrestres y aéreas que se encuentren destacadas fuera del territorio nacional", y no, en términos más restrictivos, a los militares o miembros de las Fuerzas Armadas embarcados o encuadrados en unidades terrestres o aéreas destacadas fuera del territorio nacional ${ }^{38}$.

Es indudable, a nuestro entender, que se puede estar embarcado en un buque de la Armada y no tener la condición de militar. Este sería el caso, por ejemplo, de un grupo de médicos civiles (médicos, ingenieros, traductores...) que viaje con los militares para colaborar en el desarrollo de labores de asistencia humanitaria en determinado país. Más problemas plantea la exigencia de pertenecer, sin ser militar, a una unidad mi-

38 En el seno de las Fuerzas Armadas se distinguen, como es sabido, los tres ejércitos tradicionales: Ejército de Tierra, Armada y Ejército del Aire (artículo 8 de la Constitución). 
litar terrestre o área destacada fuera del territorio nacional, pero el supuesto no es impensable, como podría perfectamente suceder con el personal de informática, de cocina o de mecánica de una unidad.

En cualquier caso, somos partidarios de hacer una interpretación amplia y flexible tanto de la fórmula "personal embarcado en buques de la Armada" como de la relativa a la exigencia de "perteneciente a unidades militares terrestres o aéreas". No se trata ya de que ninguna norma exija de forma expresa la condición de militar o de miembro de las Fuerzas Armadas en el destinatario del procedimiento, es que tampoco la finalidad de la norma induce a pensar que se encuentre exigida de forma implícita o que sea razonable exigirla.

No hay razones de peso, por tanto, para excluir del procedimiento a aquellas personas que, sin tener la categoría o condición de militar, se hallan embarcadas en buques de la Armada Española o pertenezcan -entendido este término en sentido amplio-, a unidades militares desplazadas fuera del territorio nacional y reúnan, además, los demás requisitos funcional y temporal ya señalados anteriormente. Más bien ocurre lo contrario: sería lamentable y lesivo para el derecho de sufragio que se impidiera utilizar este procedimiento a una persona, no militar, que se encontrara, por ejemplo, a bordo de un buque de la Armada, mientras se permite votar de esta forma a sus compañeros de travesía militares.

Lo dicho no debe impedir, de ninguna manera, el reconocimiento, por nuestra parte, de que la condición de militar es una característica habitual y muy frecuente entre los destinatarios de este procedimiento ${ }^{39}$. Su presencia es tan frecuente que, de hecho, en más de una ocasión, hemos hablado en este trabajo del "procedimiento de los militares desplazados fuera del territorio nacional en situaciones excepcionales" y así se titula, incluso, el trabajo en que estamos abordando su estudio ${ }^{40}$. Lo

39 El número de miembros de las Fuerzas Armadas que pueden ser usuarios de este procedimiento en unas elecciones es imposible de cuantificar con exactitud, pues las misiones en el exterior son variables. No obstante, se puede situar, grosso modo, en torno a los 2.500. Téngase en cuenta, por otra parte, que en el momento actual la cifra máxima fijada por el Gobierno de tropas militares en el exterior es de 3.000 efectivos (vid. Acuerdo del Consejo de Ministros de 29 de diciembre de 2006, que prorroga el Acuerdo de 30 de diciembre de 2005).

40 En el título de la norma reguladora de este procedimiento no se alude, en cambio, a la condición de miembro de las Fuerzas Armadas: Orden 116/1999, de 30 de abril, del Ministerio de Defensa, por la que se regula el ejercicio del derecho al voto en los procesos electorales del personal embarcado o en situaciones excepcionales vinculadas con la defensa nacional». 
hemos hecho, sin embargo, únicamente por comodidad del lenguaje, y no porque consideremos que se trate de una cualidad esencial que han de reunir los destinatarios del procedimiento.

b) El segundo comentario que queremos hacer es mucho más breve. Supone insistir, simplemente, en la defectuosa redacción del artículo 1 de la Orden Ministerial 116/1999, de 30 de abril. Este artículo lo compone un único párrafo, y nada extenso, pero en el mismo es posible encontrar numerosas deficiencias: comas desconcertantes, ilación confusa de frases, excesiva condensación expresiva en unos casos, descripciones innecesarias en otros e, incluso, traslocación de palabras $^{41}$.

Así, por ejemplo, en vez de hablar «del personal embarcado en buques de la Armada o que, perteneciendo a unidades militares terrestres o aéreas, se encuentre destacado fuera del territorio nacional, en situaciones excepcionales...", hubiera sido mejor hablar "del personal embarcado en buques de la Armada o perteneciente a unidades militares terrestres o aéreas destacadas fuera del territorio nacional, que se encuentre en situaciones excepcionales..." Con la fórmula legal no se sabe muy bien si encontrarse fuera del territorio nacional o estar en situaciones excepcionales es predicable sólo para el personal terrestre y aéreo o también para el personal embarcado.

c) En tercer lugar, queremos poner de relieve la falta de correspondencia entre el artículo 1 de la Orden Ministerial 116/1999, de 30 de abril, que regula este procedimiento, y la habilitación normativa contenida en la Disposición Transitoria Tercera del Real Decreto 605/1999, de 16 de abril, de regulación complementaria de los procesos electorales. Con independencia de cuál sea la interpretación que se realice del artículo 1 citado, el resultado al que se llega es el mismo: el defectuoso uso de la habilitación ${ }^{42}$.

Obsérvese que mientras la Disposición Transitoria Tercera habilitadora contenida en el Real Decreto 605/1999, de 16 de abril, habla, por

${ }^{41}$ Nos referimos, en concreto, al empleo de la fórmula «ejercicio del derecho de voto por correo", en vez de "ejercicio por correo del derecho de voto".

${ }^{42}$ En la anterior regulación de este procedimiento pasaba lo mismo, pues tanto la norma habilitadora (Real Decreto 421/1991, de 5 de abril, según modificación operada por Real Decreto 563/1993, de 16 de abril) como la reguladora (Orden 53/1993, de 12 de abril) tenían el mismo tenor que las actualmente vigentes. Además, hay que tener presente que en 1993 se salvó un problema de habilitación aún mayor, ya que en la redacción original del Real Decreto 421/1991, de 5 de abril, no se hacía referencia alguna al personal perteneciente a unidades militares terrestres y aéreas, sino únicamente al personal embarcado en buques de la Armada. 
un lado, del "personal embarcado en buques de la Armada, cuando se encuentre, en situaciones excepcionales, vinculadas con la Defensa Nacional, que así lo aconsejen" y, por otro lado, "del personal perteneciente a unidades militares terrestres o aéreas que se encuentre destacado fuera del territorio nacional, en las precitadas situaciones excepcionales, y que participe o coopere, con las Fuerzas de los países aliados y de Organizaciones internacionales, en misiones de asistencia humanitaria o mantenimiento de la paz internacional», el artículo 1 de la Orden Ministerial reguladora alude conjuntamente a ambos tipos de sujetos hablando «del personal embarcado en buques de la Armada o que, perteneciendo a unidades militares terrestres o aéreas, se encuentre destacado fuera del territorio nacional, en situaciones excepcionales, vinculadas con la defensa nacional y que participe o coopere, con las Fuerzas de los países aliados y de organizaciones internacionales, en misiones de asistencia humanitaria o mantenimiento de la paz internacional».

Y si esto es así sólo hay dos conclusiones posibles: o la Orden Ministerial reguladora del procedimiento estudiado incurre en un exceso de habilitación, en el caso de que consideremos aplicable al personal embarcado la referencia a la participación o cooperación en misiones de asistencia humanitaria o de mantenimiento de la paz internacional; o, por el contrario, incurre en déficit habilitador, si consideramos que esta referencia no es exigible al personal embarcado en buques de la Armada y que sólo cabe aplicarla al personal terrestre o aéreo. En cualquier caso, hay que hablar de mal uso de la habilitación normativa $y$, por ello, de mala técnica legislativa ${ }^{43}$.

d) Por último, es preciso aludir a uno de los puntos más relevantes de las relaciones entre el procedimiento de votación a distancia de los militares en el exterior y el del personal embarcado, regulado por el artículo 9 del Real Decreto 605/1999, de 16 de abril, de regulación complementaria de los procesos electorales. Nos referimos, en concreto, a la delimitación del ámbito de aplicación respectivo.

Los dos procedimientos de votación a distancia incluyen dentro de su ámbito de aplicación, como sabemos, al personal embarcado en

43 En relación con la titularidad de la potestad reglamentaria y la jerarquía de los reglamentos vid. los artículos 2, 4, 5 y 23 de la ley 50/1997, de 27 de noviembre, del Gobierno. En el ámbito doctrinal vid. José María BAÑo LEón, Los límites constitucionales de la potestad reglamentaria (remisión normativa y reglamento independiente en la Constitución de 1978), Universidad Complutense y Civitas, Madrid, 1991; y Eduardo GARCíA DE ENTERRÍA, Legislación delegada, potestad reglamentaria y control judicial, 2. ${ }^{a}$ edición, Tecnos, Madrid, 1981. 
buques de la Armada ${ }^{44}$, por lo que puede plantearse la duda de cuándo aplicar uno y cuándo el otro. La pregunta a responder es ¿qué criterio utilizar para separar los respectivos ámbitos en relación a este personal?

La clave no está, a nuestro juicio, en lo más llamativo de la Orden Ministerial 116/1999, de 30 de abril, es decir, en la concurrencia o no de las situaciones excepcionales vinculadas con la defensa nacional o con la participación o cooperación en misiones de asistencia humanitaria o de mantenimiento de la paz internacional, sino en un dato fáctico contenido en el artículo 9.1 del Real Decreto 605/1999, de 16 de abril, de regulación complementaria de los procesos electorales: la previsión o no de que durante el período electoral el buque toque puertos previamente conocidos en territorio nacional. Si es previsible la arribada del buque en un puerto español debería aplicarse el procedimiento del personal embarcado, y, en caso contrario, el procedimiento de los militares en situaciones excepcionales ${ }^{45}$.

La interpretación sistemática de las normas conduce a esta delimitación, aunque no sólo ella. También conducen al mismo lugar los antecedentes históricos. Recordemos el texto del artículo 1 de la Orden del Ministerio de Relaciones con las Cortes y de la Secretaría del Gobierno de 28 de septiembre de 1990, ya derogada, por la que se regulaba el ejercicio del derecho de voto por el personal embarcado en buques de la Armada, destinado en misiones de paz internacionales:

«Para el ejercicio del derecho de voto por correo del personal embarcado en buques de la Armada, que participe en misiones de paz internacionales, y que durante el período electoral no toque puertos del territorio español, se seguirá el procedimiento establecido en los puntos siguientes de la presente Orden ${ }^{46}$.

44 El procedimiento de los militares en el exterior afecta al personal embarcado en buques de la Armada y al personal de unidades militares terrestres o aéreas destacadas fuera del territorio nacional, mientras que el procedimiento del personal embarcado afecta, igualmente, al personal embarcado en buques de la Armada, y también al personal embarcado en buques de la Flota Pesquera y de la Marina Mercante.

45 Naturalmente, debe entenderse que la arribada del buque a puerto español debe producirse en una fase del período electoral en que sea legal y fácticamente posible ejercer a distancia el voto con arreglo a este procedimiento.

46 Esta Orden Ministerial no aludía a que los puertos tocados del territorio nacional fueran previamente conocidos, pero sólo tiene sentido que así fuera. 


\section{TRAMITACIÓN}

\section{A) Actos iniciales}

El siguiente paso en el estudio del procedimiento de votación a distancia del personal de las Fuerzas Armadas en el exterior nos lleva a abordar su tramitación, esto es, a conocer los distintos pasos que integran su desarrollo. Vamos a tratar de ser breves, sin pretender llevar a cabo un estudio detenido, punto por punto, de cada una de las fases del procedimiento, sino únicamente deteniéndonos en la implementación de las especialidades que ofrece respecto al procedimiento ordinario y al especial del personal embarcado.

Comenzaremos con los actos iniciales del procedimiento. A este respecto lo primero que hay que decir es que, ante la inexistencia de ninguna norma específica, hay que entender que el procedimiento de los militares en el exterior comienza igual que el del personal embarcado, esto es, con la manifestación de voluntad que el elector hace al Comandante del buque o Jefe de Unidad, o al Oficial en el que expresamente deleguen los anteriores, de que desea ejercer su sufragio a distancia y, en consecuencia, que se curse a la correspondiente Delegación Provincial de la Oficina del Censo Electoral (en adelante OCE) la solicitud de envío de la documentación electoral precisa para votar ${ }^{47}$.

No está prevista expresamente en ninguna norma la realización de una actividad previa de información por parte de la Administración sobre los destinatarios de este procedimiento especial de votación, aunque sería sumamente conveniente que así se hiciera. El Ministerio de Defensa debería contactar a tal efecto, nada más convocadas las elecciones, con los Comandantes de buque y Jefes de unidad concernidos y éstos informar a sus subordinados de la existencia de este procedimiento especial de votación y de la posibilidad de utilizarlo poniéndose en contacto con ellos o con los oficiales que expresamente designen ${ }^{48}$.

${ }^{47}$ Al igual que dijimos en el procedimiento ordinario sería conveniente que esta declaración de voluntad se hiciera por escrito, a los efectos de hacer frente a los posibles problemas que eventualmente pudieran surgir.

48 La previsión contenida en el artículo 3 de la Orden Ministerial de que «el Comandante del buque o el Jefe de Unidad remitirá la relación de personal que desea ejercer su derecho de sufragio al Director general de Personal del Ministerio de Defensa" no nos parece suficiente para imponer a los responsables de los buques y unidades terrestres y aéreas la obligación de información previa hacia sus subordinados. 
Y así es, además, como se suele hacer en la práctica en cada convocatoria electoral. Desde el Ministerio de Defensa, en Madrid, se emiten las instrucciones pertinentes a los responsables de los buques y unidades terrestres y aéreas. Y éstos toman conocimiento de sus obligaciones, organizan los medios personales y materiales que necesiten e informan a sus subordinados de los trámites del procedimiento ${ }^{49}$.

En cualquier caso, con independencia de que esta labor de información administrativa tenga lugar o no, lo que interesa destacar es que el procedimiento lo pone en marcha el elector de forma individual con la expresión de su deseo de votar de este modo. El personal embarcado o destacado en una unidad terrestre o aérea no tiene, pues, que esperar a que la superioridad "abra" de forma oficial el procedimiento, sino que una vez convocadas las elecciones puede dirigirse en tal sentido a su Comandante o Jefe.

Hecho esto por parte del elector, el Comandante del buque o Jefe de la unidad tiene que dar curso a la correspondiente solicitud. Lo debe hacer, lógicamente, previa comprobación, con arreglo al procedimiento ordinario, de la identidad del solicitante en el caso de no constarle ésta de forma indubitada ${ }^{50}$.

La remisión debe hacerse de la misma forma que en el procedimiento del personal embarcado, es decir, por radiotelegrafía y no por correo, como ocurre, en cambio, en el procedimiento ordinario. Esto es lo que se deduce de la regulación contenida en la Orden Ministerial 116/1999, de 30 de abril, que considera a los servicios de radiotelegrafía de los buques y unidades terrestres y aéreas como "dependencias delegadas del Servicio de Correos". No obstante, también hay que admitir la posibilidad de hacer uso de los aviones-estafeta, en la medida en que la Orden Ministerial menciona a los Comandantes de estos aparatos, sin mucho sentido a nuestro parecer, como "funcionarios encargados de la recepción de la solicitud ${ }^{51}$.

49 También tienen un papel fundamental de estímulo los medios de comunicación, los diputados y senadores con sus preguntas al Gobierno sobre este procedimiento y el propio personal militar.

$50 \mathrm{El}$ artículo 72-b de la LOREG exige que la solicitud se formule personalmente y que el funcionario de Correos encargado de recibirla exija al interesado la exhibición de su Documento Nacional de Identidad. También exige que compruebe la coincidencia de la firma, pero si no hay solicitud escrita por parte del personal militar, este requisito no se puede cumplir.

51 Vid. los artículos 3 y 6 de la Orden del Ministerio de Defensa 116/1999, de 30 de abril. 
La novedad más relevante con el procedimiento del personal embarcado estriba, sin embargo, en el órgano de remisión, pues mientras que en este procedimiento (el del personal embarcado), al igual que en el del procedimiento ordinario, la solicitud debe enviarse a la Delegación Provincial de la OCE que en cada caso corresponda, en el procedimiento que ahora estudiamos la remisión debe hacerse a la Dirección General de Personal del Ministerio de Defensa, que es quien debe contactar luego con las diferentes Delegaciones Provinciales de la OCE ${ }^{52}$. No hay, por tanto, contacto directo entre los buques y unidades militares y las Delegaciones Provinciales de la OCE.

En la Orden Ministerial 116/1999, de 30 de abril, no se indica el medio de comunicación o transporte que debe utilizar la Dirección General de Personal del Ministerio de Defensa para hacer llegar las solicitudes a las Delegaciones Provinciales de la OCE, pero se supone que debe ser el más rápido posible, por ejemplo, el fax. No tendría mucho sentido utilizar la radiotelegrafía por el simple hecho de que así es como se envían las solicitudes a las Delegaciones Provinciales en el procedimiento del personal embarcado, ni tampoco que se hiciera por correo, por ser este el medio de comunicación propio del procedimiento ordinario.

Lo que no está nada claro, sin embargo, es si la solicitud del elector se tiene que confeccionar en el buque o unidad en que se halla el elector, con la información que éste suministra (nombre y apellidos, municipio de residencia, etc.), o en la Dirección General de Personal del Ministerio de Defensa, por medio de la consulta de sus archivos. El artículo en cuestión, que es el tercero de la Orden 116/1999, de 16 de abril, dice así:

«El Comandante del buque o el Jefe de Unidad remitirá la relación de personal que desea ejercer su derecho de sufragio al Director general de Personal del Ministerio de Defensa, quien tramitará las solicitudes del certificado de inscripción en el censo a las correspondientes Delegaciones Provinciales de la Oficina del Censo Electoral a partir de la fecha de la convocatoria y hasta el décimo día anterior a la votación. Por cada solicitante se hará constar:

Nombre y dos apellidos del solicitante.

Número del documento nacional de identidad.

Fecha de nacimiento.

Provincia y municipio de nacimiento. abril.

52 Vid. el artículo 3 de la Orden del Ministerio de Defensa 116/1999, de 30 de 
Municipio de residencia en el que está incluido en el censo electoral. Calle y número de su domicilio» ${ }^{53}$.

Del tenor literal de este artículo, sobre todo en sus primeras líneas, parece deducirse que la confección de la solicitud corre a cargo de la Dirección General de Personal, mientras que los Comandantes de buque y Jefes de Unidad deben limitarse a enviar a la Dirección General la relación del personal que desea votar con arreglo a este procedimiento especial. Con ello quedaría muy descargada la labor de los responsables de los buques e incluso del propio personal que desea hacer uso de este procedimiento especial de votación.

No obstante, la solución más razonable parece ser la otra, pues nadie mejor que el elector conoce los datos relativos a su inscripción censal. Además, no hay que olvidar que, según hemos señalado antes, cabe la posibilidad de que ejerzan su sufragio con arreglo a este procedimiento personas no integradas en la organización militar, pero que, por diversas circunstancias, se encuentran embarcadas en los buques o unidades militares en el exterior. La Dirección General actuaría, por tanto, si se acepta esta interpretación, como simple órgano intermedio o de enlace entre los Comandantes de buque y Jefes de Unidad, por un lado, y las distintas Delegaciones Provinciales de la OCE, por otro, limitándose a remitir a las Delegaciones Provinciales competentes las solicitudes que le envían los Comandantes de buque y Jefes de Unidad.

De todas formas, la cuestión no tiene mayor trascendencia y consideramos que las dos opciones mencionadas son válidas $\mathrm{y}$, por tanto, susceptibles de ser aplicadas. El que se opte por una u otra depende, pues, de lo que en cada caso se considere más oportuno y eficaz por parte de los mandos civiles o militares.

Otro punto conflictivo puede ser el del plazo de presentación y remisión de las solicitudes de los electores. El artículo 3 de la Orden Ministerial señala únicamente a este respecto que el Director General de Personal del Ministerio de Defensa tramitará las solicitudes a las Delegaciones Provinciales de la OCE "a partir de la fecha de la convocatoria y hasta el décimo día anterior a la votación ${ }^{54}$, pero no establece

53 El contenido de la solicitud indicado en el artículo 3 de la de la Orden del Ministerio de Defensa 116/1999, de 30 de abril, sigue muy de cerca lo dispuesto en el procedimiento del personal embarcado (artículo 9.2 del Real Decreto 605/1999, de 16 de abril, de regulación complementaria de los procesos electorales).

${ }^{54}$ La referencia a la remisión a la Delegación Provincial de la OCE «hasta el décimo día anterior a la votación" constituye una novedad respecto al procedimiento 
plazo alguno para que los electores presenten sus solicitudes ante los Comandantes de buque y Jefes de Unidad, ni para que éstos las remitan al Director General. Tampoco alude la norma al tiempo máximo que puede transcurrir entre el momento en que el elector expresa su deseo de que se ponga en marcha el procedimiento y la transmisión de la solicitud por el responsable del buque o unidad, ni al que debe mediar entre el instante en que la solicitud llega a la Dirección General de Personal y aquel en que se recibe en la Delegación Provincial de la OCE.

Este cuadro normativo hace necesario acudir a las reglas generales del procedimiento ordinario establecidas en la LOREG y a su armonización con la única regla expresamente prevista en la Orden Ministerial que regula este procedimiento especial ${ }^{55}$. De acuerdo con ello, el elector dispone desde la convocatoria de las elecciones hasta el décimo día anterior al de la votación para presentar su solicitud (artículo 72-a LOREG), mientras el Comandante de buque o Jefe de Unidad y el Director General de Personal del Ministerio de Defensa tienen un plazo conjunto de tres días para remitir la solicitud a la correspondiente Delegación Provincial de la OCE (artículo 72-d LOREG), sin que en ningún caso puedan superar el límite del décimo día anterior a la votación (artículo 3 Orden Ministerial 116/1999, de 30 de abril).

El único problema puede surgir, como se ve, en el caso de que el elector espere al último día para presentar su solicitud de voto a distancia, pues ello obligaría al Comandante del buque o Jefe de la Unidad en que se halle a tramitar en el mismo momento la solicitud por radiotelegrafía al Director General de Personal del Ministerio de Defensa y a éste, igualmente, a remitirla de forma inmediata a la Delegación Provincial de la OCE. Si esto sucede con uno o unos pocos electores no hay problema, pero si el retraso se generaliza sí. Es por ello muy recomendable que los electores presenten su solicitud cuanto antes ante sus superiores. Además, así se aseguran de que la Delegación Provincial de la OCE va a disponer de tiempo suficiente para remitirles en plazo la documentación electoral.

ordinario y al del personal embarcado. En estos no se indica nada expresamente al respecto, por lo que rige la regla general de remisión en el tiempo más breve posible, y, en todo caso, no exceder el plazo de tres días (artículo 72-d LOREG).

${ }_{55}$ El artículo 7 de la Orden del Ministerio de Defensa 116/1999, de 30 de abril, remite expresamente al procedimiento ordinario: «En todo lo no expresamente previsto por esta Orden se estará a lo establecido en los artículos 72 a 74 de la Ley Orgánica 5/1985, de 19 de junio; en la Ley Orgánica 6/1992, de 2 de noviembre, y en la normativa de desarrollo que sea de aplicación». 
Dicho esto, es preciso aclarar el alcance que hemos dado a otro punto de la Orden del Ministerio de Defensa, en la medida en que influye en la forma que hemos resuelto la cuestión del plazo. Nos referimos de nuevo a la norma prevista en la primera parte del artículo 3, según la cual "el Comandante del buque o el Jefe de Unidad remitirá la relación de personal que desea ejercer su derecho de sufragio al Director general de Personal del Ministerio de Defensa", y en concreto a si el Comandante de buque o Jefe de unidad tiene que enviar la relación de personal de una sola vez.

A nuestro juicio, no hay razón alguna, más que la gramatical, para sostener que esta previsión supone el envío por parte del Comandante del buque o el Jefe de Unidad de una única relación de solicitudes y no de varias, conforme las vayan presentando los electores. Esta sería una interpretación rígidamente literal de la norma, que no presenta ninguna ventaja —ni facilita el ejercicio del derecho de sufragio de estos electores, ni agiliza el procedimiento, ni contribuye a la mejor gestión de las solicitudes- ${ }^{56}$, pero que puede, por el contrario, plantear algunos problemas prácticos de calado. Piénsese que si la relación de solicitudes se tramita al final del plazo legal (esto es, el décimo día anterior al de la votación), se pone en juego el éxito del conjunto del procedimiento, pues queda muy reducido el tiempo para realizar los trámites posteriores; y que, si se remite antes, el Comandante del buque o Jefe de Unidad tiene, necesariamente, que establecer, sin apoyo legal alguno, un plazo previo para la presentación de solicitudes y darle suficiente publicidad entre sus subordinados, con el riesgo siempre latente de que luego se presente, fuera de plazo, un elector con su solicitud y de que la misma le sea denegada.

\section{B) Actos intermedios}

Recibida la solicitud del elector por la correspondiente Delegación Provincial de la OCE, este órgano ha de proceder a su tramitación siguiendo las prescripciones del procedimiento ordinario, como sucede también en el procedimiento del personal embarcado. Debe, por ello, examinar la procedencia de la solicitud, comprobar que el elector está inscrito efectivamente en el censo electoral, realizar en el mismo la anotación de que el elector va a ejercer su voto a distancia, extender el

56 Lo mismo da, nos parece, que desde el buque o unidad se cursen de una vez ochenta solicitudes a que un día se cursen veinte, otro doce, otro veintiséis y el último día veintidós. 
certificado censal que le ha sido solicitado, preparar los demás documentos electorales precisos para votar $y$, finalmente, remitirle un sobre con toda la documentación antes del sexto día anterior al de la votación ${ }^{57}$.

Hay aquí, sin embargo, una pequeña diferencia con los procedimientos anteriores. La documentación electoral no se remite directamente al elector, sino, como señala el artículo 4 de la Orden 116/1999, de 30 de abril, "a la Dirección General de Personal del Ministerio de Defensa, para que, por el procedimiento más urgente posible, la haga llegar al destinatario". Ello evita, con buen criterio, la multiplicación de envíos a un mismo lugar y facilita el control sobre la buena marcha del procedimiento.

No se indica en la norma citada el procedimiento concreto que debe utilizar el Director General para hacer llegar la documentación electoral al elector, pero la rapidez que lo debe caracterizar apunta al uso de los aviones-estafeta ${ }^{58}$. Y tampoco se señala en ningún lugar a quién debe entregar el Comandante del avión-estafeta la documentación electoral, pero parece que lo más lógico es que los Comandantes de buque y Jefes de unidad sean los receptores del conjunto de los envíos y que posteriormente hagan una entrega individualizada de los mismos a los diferentes destinatarios.

En cualquier caso, siempre debería quedar constancia escrita de todos los puntos por los que va pasando la documentación electoral. Desde la entrega en la Dirección General de Personal del Ministerio de Defensa hasta la recepción final por el destinatario, pasando, por supuesto, por el Comandante del avión-estafeta y el Comandante del buque o Jefe de la Unidad en que se encuentre el elector.

\section{C) Actos finales}

Una vez que el elector tiene en su poder la documentación electoral remitida por la Delegación Provincial de la OCE tiene que emitir su voto, para lo cual debe escoger una papeleta electoral, salvo que desee votar en blanco, introducir ésta en el sobre de votación y cerrarlo. Seguidamente debe preparar el envío: tiene que introducir este sobre y el

57 Vid. el artículo 73.1 y 2 de la LOREG.

58 Su figura es mencionada de forma enigmática y, sin duda, errónea, en el artículo 6 de la Orden 116/1999, de 30 de abril, al mencionar al Comandante del avión-estafeta entre "los funcionarios encargados de la recepción de la solicitud». 
certificado de inscripción en el censo electoral en el sobre de tamaño superior dirigido a la Mesa Electoral en la que le corresponde votar.

Hasta aquí todo normal, es decir, igual que en los procedimientos anteriores. La especialidad viene ahora: el elector no remite el sobre por correo, sino que, según el artículo 5 de la Orden 116/1999, de 30 de abril, lo debe entregar al Comandante del buque o Jefe de la Unidad, el cual lo ha de custodiar, "garantizando su seguridad, integridad y secreto", hasta que sea recogido por el encargado de su transporte a territorio nacional; éste, a su vez, lo debe entregar en la Dirección General del Ministerio de Defensa, que es la que se ocupa de hacerlo llegar, antes de tercer día previo al de la celebración de las elecciones, al Servicio de Correos; y, finalmente, este Servicio lo tiene remitir con carácter urgente a la Mesa electoral correspondiente ${ }^{59}$. En todo momento, igual que dijimos con la documentación electoral, deberá dejarse constancia escrita de todas estas entregas del voto.

No se ha señalado en esta norma un plazo máximo determinado para que el elector entregue el sobre electoral al Comandante del buque o Jefe de la Unidad, pero las peculiares circunstancias del procedimiento - la remisión conjunta de los votos, la lejanía del territorio nacional, la posible coordinación con otros destacamentos militares en la organización de la recogida de los votos y la existencia de trámites posteriores a la entrega- hacen impracticable la regla del procedimiento ordinario de que el elector tenga derecho a llegar hasta el cuarto día anterior al de la celebración de las elecciones ${ }^{60}$.

Del artículo 5 de la Orden 116/1999, de 30 de abril, puede deducirse que el elector tiene como plazo máximo de entrega la llegada del encargado del transporte de los votos a España. Esta llegada se producirá, de todos modos, en torno a esta fecha límite, aunque podría ade-

59 Estas prescripciones se recogen en el artículo 5 de la Orden 116/1999, de 30 de abril, cuyo texto dice así: «El elector procederá a ejercer su derecho al voto, una vez recibida la documentación a que hace referencia el punto anterior. De los votos emitidos se hará cargo el Comandante del buque o Jefe de la Unidad, que los custodiará, garantizando su seguridad, integridad y secreto, hasta que sean recogidos por el encargado de su transporte a territorio nacional. La Dirección General de Personal del Ministerio de Defensa hará llegar los votos recibidos al organismo autónomo Correos y Telégrafos, antes del tercer día previo al de la celebración de las elecciones, el cual los remitirá con carácter urgente a la Mesa electoral correspondiente".

60 El artículo 73.4 de la LOREG establece, en relación con el procedimiento ordinario, que el elector remitirá el sobre «en todo caso antes del tercer día previo al de la celebración de las elecciones". 
lantarse un poco, e incluso sería recomendable que así sucediera para garantizar la efectividad del voto. En tal caso, lo único que tiene que hacer el Comandante del buque o Jefe de la Unidad es comunicárselo a sus subordinados, a fin de que no queden defraudadas sus expectativas.

La norma en cuestión tampoco ha individualizado o concretado el medio de transporte de los votos ni el funcionario que ha de responsabilizarse del traslado y posterior entrega de los votos en la Dirección General del Ministerio de Defensa en España. No obstante, parece que el medio más adecuado será el avión-estafeta y el funcionario responsable el Comandante del mismo ${ }^{61}$.

Finalmente, una vez que la Dirección General del Ministerio de Defensa ha entregado los sobres electorales al Servicio de Correos, deben sucederse, sin especialidad alguna, las demás fases que integran el procedimiento ordinario de votación a distancia y que ya nos son conocidas. En primer lugar, el Servicio de Correos debe proceder a la tramitación de los votos: traslado de los sobres a las oficinas postales de las localidades donde estén las Mesas Electorales de destino y posterior entrega en las Mesas de los sobres el día de la votación. Y en segundo término, y como acto final, debe tener lugar la materialización de los sufragios por parte de cada una de las Mesas Electorales, con todas las operaciones de control que ello implica.

\section{CONSIDERACIONES FINALES}

\section{A) El deficiente funcionamiento del procedimiento}

El procedimiento de los militares destacados fuera del territorio nacional merece, en principio, un juicio que podríamos calificar como discretamente positivo; desde luego, más positivo que el que suscitan otros como, por ejemplo, el procedimiento del personal embarcado. Nos parece que, en líneas generales, responde a los desafíos que plantea el voto a distancia de un grupo de personas que, por razones laborales, se hallan alejadas del territorio nacional, muchas veces en situaciones muy difíciles.

61 Igual, por tanto, que lo señalado para el traslado de la documentación electoral desde España a los buques y unidades, por lo que cabe la posibilidad de aprovechar el mismo viaje para entregar la documentación electoral y recoger, poco después, los votos. 
No obstante, el procedimiento no ha funcionado bien en la práctica, como ponen de relieve los datos del voto de los marineros y soldados destinados en Irak durante las elecciones locales y autonómicas de 25 de mayo de 2003, las últimas elecciones de que tenemos datos completos y fiables del voto de este colectivo ${ }^{62}$ : de los más de setecientos potenciales electores tan solo 146 cursaron la solicitud de voto a distancia; los sobres de documentación electoral recibidos de las distintas Delegaciones Provinciales de la OCE y remitidos por la Dirección General de Personal a Irak antes del cuarto día anterior al de la votación fueron 34; y los votos recibidos desde Irak para su posterior remisión a las Mesas Electorales antes de las veintidós horas del tercer día previo a la votación fue cero (!!! $)^{63}$.

Estos datos son decepcionantes y muy reveladores. $Y$ auque todo apunta a que la situación ha mejorado con posterioridad - sin que, repito, podamos aportar datos completos al respecto- también tenemos constancia de que el problema persiste. Se podría decir, si se me permite la expresión, que el paciente mejora, pero sigue estando grave.

Ello nos lleva a plantearnos el por qué de esta ineficacia del procedimiento. Dicho de otro modo: ¿a qué o a quién se debe esta lamentable situación? Lo primero que cabe pensar es en el factor tiempo. Los plazos del procedimiento son, como todo el mundo se habrá dado cuenta, demasiado amplios, lo que hace que la tarea de emisión y remisión del voto por el elector se desplace a unas fechas muy avanzadas del calendario electoral.

No creemos, sin embargo, que ésta sea la causa principal del deficiente funcionamiento de este procedimiento, sino, en general, la dejadez de la Administración, que, a nuestro juicio, no se ha preocupado lo suficiente de cumplir los plazos de actuación que tiene establecidos. Obsérvese, continuando con el ejemplo de Irak de las elecciones de mayo de 2003, el siguiente dato: la Dirección General de Personal del

62 Estos datos han sido suministrados al Congreso de los Diputados por el Secretario de Estado de Relaciones con las Cortes, en respuesta a una pregunta formulada por la diputada del Grupo Socialista María Carmen Sánchez Díaz. Vid. el Boletín Oficial de las Cortes Generales, Congreso de los Diputados, Serie D, núm. 567, de 11 de julio de 2003, pp. 211-213. Para la pregunta vid. el Boletín Oficial de las Cortes Generales, Congreso de los Diputados, Serie D, núm. 549, de 11 de junio de 2003, p. 124.

63 El artículo 73.3 de la LOREG establece como fecha límite para remitir el sobre con el voto el tercer día previo a la celebración de las elecciones. No obstante, la Junta Electoral Central lo suele prorrogar hasta las 22 horas del día siguiente. 
Ministerio de Defensa remitió, en plazo, a las Delegaciones Provinciales de la OCE 146 solicitudes, pero ocho días después solo habían Ilegado a dicha Dirección General la documentación correspondiente a 34 solicitudes. Y este trámite era, además, el más fácil de cumplir, pues tiene lugar exclusivamente en territorio nacional por los mecanismos habituales del procedimiento ordinario ${ }^{64}$.

\section{B) Propuestas para un mejor funcionamiento}

A la vista de lo que acabamos de apuntar, creemos que todo el mundo estará de acuerdo en la necesidad de tomar medidas. Ahora bien, ¿qué medidas? En esto es, sin duda, más difícil hallar el consenso. Cada estudioso e incluso cada persona que haya estado en contacto directo con el procedimiento tendrá, sin duda, su receta, pero ante la falta de opiniones publicadas nos limitaremos a exponer la nuestra.

Lo primero que queremos indicar es que el voto por internet podría ser una alternativa válida para este colectivo. No obstante, no perderemos el tiempo en su defensa, pues su reconocimiento individualizado, es decir, únicamente en este procedimiento, es inviable, pues impediría radicalmente el secreto del voto de sus usuarios. Sería necesaria, por tanto, una implantación más amplia de este tipo de voto para lo cual nos parece que todavía faltan algunos años.

Nos inclinamos, por ello, por una reforma limitada del procedimiento, a fin de conseguir una mejora significativa de su funcionamiento. Se trataría, en pocas palabras, de introducir medidas encaminadas a encauzar más directamente al objetivo pretendido las actuaciones políticas y administrativas.

En este sentido proponemos, en concreto, que se introduzcan en la Orden Ministerial que regula el procedimiento de votación de los militares en el exterior las cuatro modificaciones siguientes:

a) Relevar a la Dirección General de Personal del Ministerio de Defensa de las funciones que actualmente tiene encomendadas y atribuírselas a un órgano específico de la Administración Electoral como la Junta Electoral Central o la Oficina del Censo Electoral. Las ventajas del traslado son evidentes: no sólo se gana en relación con el principio de

64 Sobre este dato vid. el Boletín Oficial de las Cortes Generales, Congreso de los Diputados, Serie D, núm. 567, de 11 de julio de 2003, pp. 211-213. 
especialidad de funciones, sino también con el de independencia política de los órganos que gestionan las elecciones ${ }^{65}$.

b) Imponer a la Administración la obligación de informar cumplidamente a los destinatarios del procedimiento tanto de su existencia como de los pasos que jalonan su tramitación. Lo más lógico sería que un órgano como la Junta Electoral Central o la Oficina del Censo Electoral se pusiera en contacto, directamente o por medio del Ministerio de Defensa, con los Comandantes de buque y Jefes de Unidad y que luego éstos trasladaran la información a sus subordinados.

c) Atribuir a un órgano concreto de la Administración Electoral (la Junta Electoral Central o la Oficina del Censo Electoral, mejor que la Dirección General de Personal del Ministerio de Defensa) la tarea de vigilar y estimular el cumplimiento de sus obligaciones por parte de las Delegaciones Provinciales de la OCE, los Comandantes de los aviones-estafeta, los Comandantes de buque y Jefes de Unidad y el Servicio de Correos. Se trata, simplemente, de que haya alguien pendiente de que todo marche como debe marchar.

d) Establecer plazos específicos, más reducidos que los actuales, en los diferentes trámites a cumplir. Así, por ejemplo, debería adelantarse un par de días o tres el plazo máximo de que disponen las Delegaciones Provinciales de la OCE para remitir a los electores la documentación electoral, plazo que se sitúa actualmente en el séptimo día anterior al de la votación ${ }^{66}$.

\section{C) Otros aspectos a mejorar}

Finalmente, tenemos que referirnos a otros aspectos del procedimiento estudiado que consideramos francamente mejorables, con in-

${ }^{65}$ La Junta Electoral Central y la Oficina del Censo Electoral son órganos que ejercen de forma ordinaria diversas funciones electorales, mientras que la Dirección General de Personal del Ministerio de Defensa sólo lo hace en este caso concreto. Además, son órganos que tienen un perfil bastante más independiente y neutral que el de la Dirección General citada.

${ }^{66}$ El artículo 73.3 de la LOREG establece actualmente que «la Oficina del Censo Electoral remitirá por correo certificado al elector, a partir del trigésimo cuarto día posterior a la convocatoria y antes del sexto día anterior al de la votación, al domicilio por él indicado o, en su defecto, al que figure en el censo, las papeletas y los sobres electorales, junto con el certificado mencionado en el párrafo anterior [certificado de inscripción en el censo electoral] y un sobre en el que figurará la dirección de la Mesa donde le corresponda votar. Con los anteriores documentos se adjuntará una hoja explicativa». 
dependencia de que no hayan tenido responsabilidad efectiva alguna en el mal funcionamiento del procedimiento. Se trata de cuestiones en cierto modo de carácter técnico, en la mayoría de los casos de técnicalegislativa.

Las indicaciones críticas a efectuar en este terreno podrían ser muy numerosas, pero nos vamos a centrar en las tres que consideramos más relevantes:

a) En primer lugar, hay que referirse al hecho de que al legislador se le ha olvidado otorgar a determinados sujetos (al Director General de Personal del Ministerio de Defensa, a los Comandantes de los avionesestafeta, a los Comandantes de buque y Jefes de Unidad y a los Oficiales en que expresamente deleguen éstos) la consideración de funcionarios encargados de entregar la documentación electoral a los electores y de recibir de éstos los sobres con el voto. El artículo 6 de la Orden del Ministerio de Defensa 116/1999, de 30 de abril, reconoce a estos sujetos, y a los efectos previstos en los párrafos a) y b) del artículo 72 de la LOREG, la condición, únicamente, de "funcionarios encargados de la recepción de la solicitud", sin darse cuenta de que luego, en el articulado de la norma, se le atribuyen funciones no sólo en este terreno, sino también en el de la entrega de la documentación electoral y en el de la recepción de los sobres con los votos ${ }^{67}$.

b) Otro aspecto negativo, al que ya nos hemos referido en otro momento, es el de la deficiente delimitación del ámbito de aplicación

67 La subsanación de este error sería muy sencilla, pues bastaría con modificar el artículo 6 de la Orden 116/1999, de 30 de abril, para aludir en el mismo al artículo 73.2 y 3 de la LOREG y a la condición de funcionarios encargados de entregar la documentación y de recibir los sobres con los votos de diversos sujetos (Director General de Personal del Ministerio de Defensa, Comandantes de los aviones-estafeta, Comandantes de buque y Jefes de unidad y Oficiales en que expresamente deleguen éstos). El texto quedaría más o menos así: "A los efectos previstos en los párrafos a) y b) del artículo 72 de la Ley Orgánica del Régimen Electoral General, los servicios de radiotelegrafía de los buques o de las unidades tendrán la consideración de dependencias delegadas del Servicio de Correos, y los Comandantes de buque y Jefes de unidad, o el Oficial en el que expresamente deleguen, así como el Comandante del avión-estafeta y el Director General de Personal del Ministerio de Defensa la de funcionarios encargados de la recepción de la solicitud. Igualmente, y a los efectos del artículo 73.2 y 3 de la Ley Orgánica 5/1985, de 19 de junio, del Régimen Electoral General, el Director General de Personal del Ministerio de Defensa, los Comandantes de los aviones-estafeta, los Comandantes de buque y Jefes de Unidad, o el Oficial en que expresamente deleguen, tendrán la condición de funcionarios encargados de entregar la documentación electoral y de recibir los sobres con los votos". 
del procedimiento. Se puede afirmar, diciéndolo con pocas palabras, que el mismo no está todo lo claro que sería deseable, dando lugar a una especie de galimatías para intérpretes esforzados. Sería conveniente, por ello, clarificar dicho ámbito de aplicación y hacerlo, además, en el sentido más generoso posible.

c) Por último, hay que decir que nos parece criticable el hecho de que no se haya establecido ninguna clase de control interno o externo sobre la recepción y custodia de los votos por parte tanto de los Comandantes de los buques o Jefes de Unidad, como de la Dirección General de Personal del Ministerio de Defensa ${ }^{68}$. Los primeros actúan en solitario y, además, se encuentran en estrecha dependencia del Gobierno; la Dirección General de Personal suscita, por su parte, todavía más reticencias, pues la ocupación de su cúspide por personas nombradas directamente por el Gobierno le concede un elevado perfil político.

Ninguno de ellos reúne, por tanto, las más elementales garantías de neutralidad e independencia propias de la Administración Electoral. Y si estas garantías son necesarias en todo órgano que tenga tareas administrativas que cumplir en el proceso electoral, resultan absolutamente imprescindibles cuando se trata de una cuestión tan sensible como la gestión y custodia de los votos de los ciudadanos ${ }^{69}$.

Esta deficiencia ha sido observada, además, por los propios militares y condujo en las elecciones generales de 14 de marzo de 2004 a que

68 Existen aquí dos tipos de riesgo. El primero afecta a la tramitación efectiva del voto por los órganos depositarios, concretándose en la posible dilatación o impedimento de la misma. El otro se refiere a la violación del secreto del voto o a la sustitución, incluso, de la voluntad electoral expresada por el elector. Para hacer frente al primer riesgo no se nos ocurre más opción que el control efectivo de la Junta Electoral Central y el reconocimiento del derecho de acceso de los partidos políticos y de los propios interesados a la información sobre la tramitación del voto. En cuanto al segundo peligro la solución se complica. No es nada fácil articular mecanismos de control sencillos en este terreno, aunque no imposible. Por ejemplo, cabe pensar en la exigencia de que los usuarios del procedimiento rubriquen con su firma la cara externa y el cierre de los sobres electorales e incluyan dentro del mismo una declaración jurada con su firma; la Mesa Electoral podrá luego comprobar la coincidencia de la firma y actuar en consecuencia. Otro mecanismo posible: utilizar sobres de seguridad, de tal forma que la apertura por un tercero con posterioridad a su cierre por el elector sea fácilmente detectable.

69 Sobre la necesaria independencia de los órganos encargados de la administración y control del proceso electoral vid. W. J. M. MACKENZIE, Elecciones libres, traducción española de F. Condomines Pereña, Madrid, Tecnos, 1962, pp. 109-110 (edición original: Free elections, 1957). 
en la base de Diwaniya, en Irak, se creara una especie de órgano de gestión y control formado por el Comandante interventor y el asesor jurídico. Se encargó de presenciar y dar fe del depósito de los votos y de organizar su custodia ${ }^{70}$.

$$
* * * * *
$$

A la vista de todas estas consideraciones finales, se puede concluir que el procedimiento especial de votación del personal de las Fuerzas Armadas es susceptible de mejora, sin necesidad de introducir grandes cambios en el conjunto del mismo y sin que, por otra parte, resulte afectada la coherencia del sistema de emisión del voto en España. Se podría decir, tomando prestadas las palabras del filósofo Fernando Savater, que se trata de ser "audaces, muy audaces, pero no demasiado audaces".

\section{Title}

SUFFRAGE RIGHT ACTIVITY BY SPANISH ABROAD ARMY STAFF. ORDEN 116/1999'S SPECIAL PROCESS CRITICAL REVIEW

\section{Resumen}

El objeto de este trabajo es examinar críticamente la regulación del procedimiento especial de votación del personal de las Fuerzas Armadas destacado en el exterior. Se trata de situar el procedimiento en su contexto histórico y normativo, de analizar y evaluar tanto las especialidades que presenta respecto del procedimiento ordinario de votación a distancia, como el ámbito exacto en el que se aplica y los trámites que lo integran $y$, finalmente, de trazar una serie de propuestas en orden a su mejor y más coherente funcionamiento.

\section{Abstract}

This study aims to balance, with critical perspective, the abroad Army Staff's special process of vote. The paper tries to place that process in the right historical and normative context, to analyze and assess its specialities in relation with the regular process of abroad vote, as well as its proper way of aplication and procedure. And, finally, it tries to achieve some suggestions in order to get a better and more coherent working of the process.

70 Apud, por ejemplo, El País, de 1 de marzo de 2004. 


\section{Summary}

I. PRESENTATION. II. REGULATION. A) Normative context. B) Actual regulation and historical precedents. III. SPECIALITIES. A) Links with on board Staff process. B) Certain specialities. IV. APLICATIONWIDE. A) Delimitation trouble. B) Process's droits of aplication. C) Some other significant accuracies.. V. PROCEDURE. A) Begining acts. B) Middle-process acts. C) Ending acts. VI. FINAL CONSIDERATIONS. A) Process bad working. B) Improving suggestions. C) Other issues to improve.

\section{Palabras clave}

Elecciones; derecho electoral; derecho de sufragio, fuerzas armadas.

\section{Key words}

Elections, suffrage law, suffrage right, Army. 